\title{
Soares de Passos, Álvares de Azevedo e as diversas faces do ultra-romantismo
}

\author{
Luciene Marie Pavanelo ${ }^{1}$
}

\begin{abstract}
RESUMO: O ultra-romantismo português e brasileiro produziu dois poetas que possuem convergências e divergências, na medida em que refletem as contradições de uma época instável, marcada pela consolidação das mudanças iniciadas pelas revoluções dos setecentos e vivenciadas de maneiras distintas nos dois países. Comparar as obras de Soares de Passos e Álvares de Azevedo é uma tentativa de desvendar o pensamento de um período heterogêneo, multifacetado e mais complexo do que aparenta ser.
\end{abstract}

ABSTRACT: Portuguese and Brazilian ultra-romanticism produced two poets that have convergences and divergences, once they reflect the contradictions of an instable time, marked by the consolidation of the changes introduced by the $18^{\text {th }}$ century revolutions and experienced in distinct ways in both countries. Comparing Soares de Passos and Álvares de Azevedo's works is an attempt of uncovering the thought of a period that is heterogeneous, multifaceted and more complex than it looks like.

PALAVRAS-CHAVE: Ultra-romantismo; Poesia; Portugal; Brasil

KEYWORDS: Ultra-romanticism; Poetry; Portugal; Brazil

A chamada "primeira geração romântica", em Portugal e no Brasil, tinha como principais motes a defesa do nacionalismo e do sentimentalismo na literatura, características presentes em praticamente todos os primeiros romantismos. De acordo com Nachman Falbel, o romantismo é fruto das Revoluções Francesa e Industrial, que provocaram fortes abalos nas instituições politicas tradicionais: “o nacionalismo nesse tempo irrompe impetuosamente em cena, arrastando consigo boa parte dos povos europeus em direção às suas aspirações políticas e sociais” (2002, p. 24). Já o sentimentalismo, como

\footnotetext{
1 Doutoranda do Programa de Pós-Graduação em Estudos Comparados de Literaturas de Lingua Portuguesa da Universidade de São Paulo (USP). Camilo Castelo Branco e Joaquim Manuel de Macedo: convergências na ascensão do romance nas periferias do capitalismo. Contato: lucienemp@yahoo.com.br
} 
explica Arnold Hauser, "serve à burguesia como um modo de expressar sua independência intelectual com relação à aristocracia (...), [que] era reservada e autocontrolada" (2003, p. 558).

Segundo Carlos Reis e Maria da Natividade Pires, o ultraromantismo, "enquanto resultado de uma certa evolução do Romantismo, (...) possui, apesar de tudo, uma autonomia relativa, (...) que (...) se traduz numa produção literária própria, desenrolada entre os anos 40 e os anos 60 do século XIX" ([199?], p. 246). Portugal vivia, nesse momento, um período de relativa calmaria após praticamente meio século de guerras civis, marcado pela consciência do atraso do país em relação ao restante da Europa. Imperava então a imagem da decadência iniciada com a invasão napoleônica em Portugal, em 1807, e a consequente fuga da família real ao Brasil - que acabou por se tornar sede da capital do Império -, mergulhando gradativamente o país num clima de pessimismo e desilusão.

Encontramos, nesse contexto, a obra de António Augusto Soares de Passos (1826-1860), que publicou seus primeiros poemas em 1852, no jornal O Bardo, reunidos posteriormente em 1856, no livro Poesias, juntamente com outras composições. Observamos a recorrência de alguns temas em sua obra, como o da decadência do país, constante na literatura portuguesa do século XIX. A imagem da decadência presente é contrastada com a grandeza do passado, sugerida metaforicamente em "O Outono”: “... o passado cheio de viço e frescura, / E o presente sem verdura / Como a folhagem do chão" (1983, p. 25). No poema "À Pátria”, por sua vez, essa idéia remete explicitamente à situação do país: "Ditosa e grande quando foi potente, / Hoje abatida, sem poder, sem nada" (1983, p. 39).

A grandeza passada está representada no poema "A Camões" pelo autor de Os Lusiadas, que não por acaso é escolhido como herói nacional - "Como um astro brilhante o mundo o admira" (1983, p. 19) -, por ter glorificado as navegações, época da supremacia de Portugal: "No brado heróico da guerreira tuba / O valor português soa tremendo" (1983, p. 21). Recorrente na literatura da época, a morte de Camões é 
associada à morte de Portugal: "Da pátria e do cantor findava a sorte: / Aos dois juraram perdição e morte, / E os dois juntaram na mansão funérea..." (1983, p. 21). Também são exaltados como heróis, em "O Mosteiro da Batalha", os reis do passado grandioso do país:

Fernando, Pedro, e Henrique, os três infantes;

Henrique, o sábio audaz que outro hemisfério

Primeiro abriu aos lusos navegantes.

Duarte e João segundo descansando

D’altas vitórias (...)

Dormi em paz, ó chefes do passado, (...)

Recordando os lauréis da vossa gente (1983, p. 170).

A imagem da decadência presente no poema "Outono", entretanto, é vista como passageira, uma vez que existe uma esperança de renovação: “Após o inverno sombrio / Vem a flórea primavera, / Que novos encantos gera, / Nova alegria produz" (1983, p. 26). Mais uma vez, a metáfora é revelada em "À Pátria", no qual encontramos a mesma esperança para Portugal: "No seio de teus filhos inda resta / Fogo bastante para dar-te vida" (1983, p. 42). Aliadas à decadência do país, encontramos as injustiças sociais, denunciadas em "O Mendigo": "Vaguei pelo mundo (...) / Colhendo os insultos que ao pobre se dão; / Sem pão, sem abrigo, por noites geladas / Pousei minha fronte nas lájeas do chão" (1983, p. 124). Tal idéia é reforçada em "Liberdade": "Que tristeza quando penso / Nos povos em servidão!" (1983, p. 111). Para o poeta, que se restringe à lamentação, existe apenas a salvação vinda de Deus, seja através da morte no primeiro poema - "Que vezes a morte chamei sem alento / (...) / Só hoje me ouviste! bem hajas, Senhor!" (1983, p. 125) -, ou do retorno de Cristo no segundo:

Vossa aurora bonançosa,

(...)

Vós a vereis triunfante, Qual no Gólgota brilhou, Quando toda a humanidade

Uma voz - fraternidade,

Lá duma cruz ressoou

Um dia essa voz (...)

Retumbará pela terra 
Como a trombeta final...

(...)

As nações hão-de enlaçar-se;

Os homens hão-de sentar-se

Ao banquete fraternal (1983, p. 117-118).

A exaltação do cristianismo é recorrente na obra de Soares de Passos, que dedicou parte de seus poemas para louvar a Cristo e a Deus. Encontramos tal louvor em "O Gólgota": "Ó Cristo! foi sublime a tua vida / (...) / No amor, na crença, doutrinando o mundo / Foste o Messias d'inspirado alento; / Ensinando o perdão e o sofrimento / Foste inda o homem Deus!" (1983, p. 62). Este poema, que possui um claro tom moralizante, mostra a concepção dos valores cristãos como reformadores da sociedade: "Um Deus, um Deus à terra se apresenta / A resgatá-la dos grilhões do vício" (1983, p. 62). Já em "O Firmamento", por sua vez, o poeta utiliza-se do cientificismo e dos conhecimentos de astronomia para ressaltar a pequenez do homem, da Terra e do universo perante Deus:

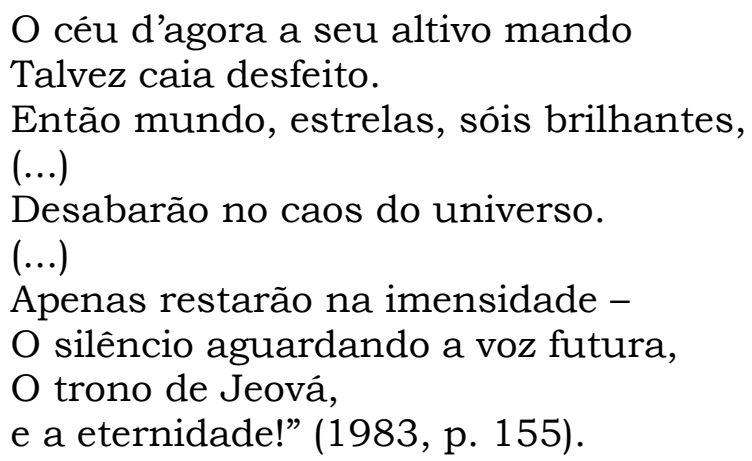

Em Soares de Passos, a descrição da paisagem aparece, primeiramente, como um ensejo para a exaltação de Deus, como vemos em "Canto de Primavera": "Cantai, ó aves módulas, / Cantai em coro ledo! / Murmúrios do arvoredo, / Cantai a Jeová! / (...) / Dizendo noite e dia: / - Hossana ao Criador!" (1983, p. 98). Além disso, a paisagem também se encontra a serviço da ambientação para o amor em, por exemplo, "Canção": "o trinado / Lá volta enlevado, / Das noites o amado, / Da selva o cantor; / E o hino que entoa / No bosque ressoa / E ao longe revoa, / Gemendo d'amor" (1983, p. 37). 
O sentimentalismo percorre grande parte de seus poemas, como em "Desejo", no qual afirma que "a vida é só vida se o amor nela acende / Seu doce fanal" (1983, p. 32). O eu-lírico ressalta essa devoção ao amor no poema "A Ti": "Tudo a meus olhos, tudo sorri; / É que ali vejo só tua imagem, / É que hoje vivo, mas só por ti” (1983, p. 71). O ideal de mulher é a bela, inocente, virgem, associada à imagem de anjo em "Amo-te": “... amo tu'alma inocente, / Tão pura que os anjos mais pura a não tem / (...) ó virgem celeste" (1983, p. 108). Neste poema, é possível encontrarmos uma mulher que também possui o seu lado carnal: "Mas inda mais amo sorver a doçura / Dos beijos que, ardendo, teus lábios me dão" (1983, p. 108). Com isso, a poesia de Soares de Passos se reveste de uma espécie de erotismo paradoxalmente celestial: "Eu amote, ó anjo que à terra vieste, / O amor ensinar-me dos anjos dos céus" (1983, p. 108).

Também recorrente é o tema da realização do amor na morte, encontrado em "O Noivado do Sepulcro", poema que fez grande sucesso na época. A morte, nesse caso, é vista de forma positiva, ao unir os dois amantes: "Dois esqueletos, um ao outro unido, / Foram achados num sepulcro só" (1983, p. 30). Ela também é positiva em "Amor e Eternidade", no qual ressalta a perenidade do amor: "Nada receies, pois: a tumba encerra / Um breve espaço e uma breve idade! / E o amor tem por pátria o céu e a terra, / Por vida a eternidade!” (1983, p. 82). No poema "À Morte", por sua vez, o eu-lírico afirma que nela "terás as harmonias / Que soltam milhões d'esferas, / E florentes primaveras / Quais não terias aqui” (1983, p. 122).

A busca da morte como fuga da realidade e dos dilemas sociais é idéia que pode ser vista em "Enfado", poema embasado na misantropia: "Dos homens, ai quem me dera / Longe, bem longe viver!" (1983, p. 47). No poema "A Vida", temos a imagem de um eu-lírico desiludido: "As ilusões do amor se desvanecem: / (...) / Honras, glórias, poder, bens de fortuna, / Ciência austera, festivais prazeres, / A tudo se abalança, aspira a tudo, / E em tudo encontra desenganos sempre" (1983, p. 127128). Para ele, não há alívio nem na vida ascética: "Feliz aquele que em 
modesta lida, / Isento da ambição e da miséria, / No regaço do amor e da virtude / A vida passa (...) / Mas, que digo! nem esse. Infindos males, / Comuns a todos, seu viver não poupam” (1983, p. 129). Sendo assim, a morte é a única saída possivel: "Morte, morte, bem vinda sejas sempre" (1983, p. 132). Quando pensamos que o poeta finalmente desistiu e se entregou ao ceticismo, surge a voz de Deus, trazendo esperança: "Fanal de salvamento, luz d'esperança, / Que na altura do Gólgota brilhaste, / Desce à minha alma que a tristeza inunda! / (...) / Soframos e esperemos! / Depois da noite escura vem o dia" (1983, p. 133).

É possivel encontrarmos certa regularidade de pensamento em Soares de Passos, poeta que defende o nacionalismo através da exaltação à pátria, a qual, apesar de ser vista como decadente, ainda pode ser reerguida. Alguns de seus poemas refletem uma preocupação em celebrar heróis nacionais do passado, que ajudam a engrandecer a imagem do país e resgatar a sua origem, procedimento tipicamente romântico, comumente ilustrado a partir do culto à Idade Média. À denúncia das injustiças sociais se segue a salvação vinda de Deus, através da religião cristã, vista como reparadora dos vícios da sociedade. A descrição da paisagem não está a serviço de pintar a cor local, como comumente encontramos nos primeiros romantismos, mas antes para louvar a Deus e para a ambientação do amor.

Em sua poesia o sentimentalismo é exaltado, e a mulher é paradoxalmente vista como o ideal de pureza conjugado com a fonte de prazer carnal, ainda que pelo beijo e não pelo ato sexual, uma vez que o ideal de pureza está relacionado à virgindade. A idéia da morte é associada à felicidade ou alivio, pois traz a realização do amor para a eternidade e remete à fuga das dificuldades da vida e dos problemas sociais encontrados no mundo físico. Como veremos a seguir, a obra de Álvares de Azevedo possui pontos de convergência e divergência com a do poeta português.

Manuel Antônio Álvares de Azevedo (1831-1852) escreveu a sua obra entre 1848 e 1852, publicada um ano após a sua morte, época em 
que o nacionalismo, o indianismo e o sentimentalismo românticos estavam em voga no Brasil. O país vivia nesse momento um clima de otimismo provocado pelo progresso da colônia, iniciado com a vinda de D. João VI, seguido de sua promoção à sede do Império e sua conseqüente Independência, acontecida duas décadas antes, e que, por sua vez, acabou desencadeando a necessidade da formação de um "espírito de nacionalidade" até então inexistente.

Segundo Antonio Candido, encontramos em Álvares de Azevedo "o emprego da discordância e do contraste, como corretivo a uma concepção estática e homogênea de literatura" (1964, p. 178). Se, por um lado, há momentos (como nos poemas da primeira parte da Lira dos Vinte Anos) em que concorda com a ideologia vigente, o que o aproximaria de alguns temas encontrados em Soares de Passos, por outro Azevedo coloca-se como opositor dessa mesma ideologia (como nos poemas da segunda parte da Lira, nos contos de Noite na Taverna e na peça Macário), fazendo uso da auto-ironia. O poeta explicara no prefácio da segunda parte da Lira que "a unidade deste livro [e de toda a sua obra] funda-se numa binomia. Duas almas que moram nas cavernas de um cérebro pouco mais ou menos de poeta escreveram este livro, verdadeira medalha de duas faces" (2000, p. 190).

Na obra de Álvares de Azevedo não encontramos exaltações à pátria, uma vez que, segundo Candido, para o autor "a dimensão cosmopolita é um pressuposto aceito e conscientemente incorporado como algo legítimo e necessário" (1989, p. 14). Em Macário, Azevedo ridiculariza a ideologia nacionalista da época, definindo-a como discurso dos "oradores de lugares comuns que não sabem o que dizem" (2000, p. 549). O herói nacional na literatura brasileira, como aparece nos poemas de Gonçalves Dias, era o índio que, se não foi criticado por Álvares de Azevedo, ao menos acabou ignorado. O que o autor nos mostra no poema "Boêmios", ao contrário do que encontramos em Soares de Passos, é a dessacralização dos setores sociais representantes do Antigo Regime, como os reis - "E demais é bem sabido / Que El-Rei só reina à mesa e nas caçadas" (2000, p. 218) - e o clero: 
Abertos garrafões; garrafas cheias;

Vinho em copos imensos transbordando;

Na toalha, já suja, debruçados

Aqueles religiosos cachaçudos

De boca aberta e de embotados olhos.

Gastrônomos! ali é que se via

Que é ciência o comer, e como um frade

Goza pelo nariz e pelos olhos,

Pelas mãos, pela boca, e faz focinho

$\mathrm{E}$ bate a lingua ao paladar gostoso

Ao celeste sabor de um bom pedaço! (2000, p. 219).

Dessa forma, ainda que no poema "Hinos do Profeta", presente na primeira parte da Lira, a imagem de Deus como fonte de alivio para as aflições do homem seja a mesma que no poeta português - "E agora o único amor... o amor eterno, / Que no fundo do peito aqui murmura / E acende os sonhos meus / (...) / Que lança algum luar no meu inverno, / Que minha vida no penar apura, / É o amor de meu Deus!" (2000, p. 179) -, a religião, corrompida, não é vista como fonte de salvação. A denúncia das injustiças sociais aparece na segunda parte da Lira em "Dinheiro", no qual não encontramos nenhuma perspectiva de mudança:

Fora a canalha de vazios bolsos!

O mundo é para todos... Certamente

Assim o disse Deus - mas esse texto

Explica-se melhor e doutro modo.

Houve um erro de imprensa no Evangelho:

O mundo é um festim, concordo nisso,

Mas não entra ninguém sem ter as louras (2000, p. 245).

Em suas obras de temática maldita, encontramos a imagem de Satã, responsável pela germinação do ceticismo, da dúvida, do questionamento às imposições da sociedade, aos seus valores e à sua ordem: nas palavras de Macário, "talvez um anjo mau soprasse no meu espírito as cinzas sufocadoras da dúvida" (2000, p. 552). A vida desregrada aparece como pressuposto estético desses textos, praticada em Noite na Taverna e defendida em Macário: "A vida está na garrafa de Cognac, na fumaça de um charuto de Havana, nos seios voluptuosos da morena" (2000, p. 549). A estética macabra, que aparece em Noite e 
culmina na necrofilia do seu último episódio, não aparece em Soares de Passos, que se limita a utilizar apenas o elemento funéreo em "O Noivado do Sepulcro".

Álvares de Azevedo, assim como Soares de Passos, também faz a exaltação do amor em "Vida", poema da primeira parte da Lira: "A nós a vida em flor, a doce vida/ Recendente de amor! / Cheia de sonhos, d'esperança e beijos” (2000, p. 160). O eu-lírico mostra a concepção romântica de mulher, explicitada na fala de Macário, quando perguntado o que exigiria para a mulher de seus amores: "pouca coisa. Beleza, virgindade, inocência, amor...” (2000, p. 519). Todavia, para Azevedo, o amor com essa mulher idealizada jamais é realizado, ficando o poeta somente com o seu desejo, como no poema "A T...": "Nas longas noites / Adoeço de amor e de desejos / E nos meus sonhos desmaiando passa / A imagem voluptuosa da ventura...” (2000, p. 146). Nas obras de temática maldita, por sua vez, é possivel encontrarmos a satisfação dos desejos, realizada, em sua maioria, através de prostitutas.

A descrição da paisagem na primeira parte da Lira, presente em "A Cantiga do Sertanejo", tal como em Soares de Passos, também está a serviço da ambientação para o amor: "Se tu viesses, donzela, / Verias que a vida é bela / No deserto do sertão / Lá tem mais aroma as flores / E mais amor os amores / Que falam no coração!” (2000, p. 131). Álvares de Azevedo, porém, dessacraliza o sentimentalismo romântico, tornado ridículo no famoso poema "É Ela! É Ela! É Ela!", da segunda parte da Lira, que conta a paixão do eu-lírico por uma lavadeira: "roubei do seio dela / Um bilhete que estava ali metido... / Oh! decerto... (pensei) é doce página / Onde a alma derramou gentis amores; / (...) / Abri cioso a página secreta... / Oh! meu Deus! era um rol de roupa suja!" (2000, p. 238).

Em Álvares de Azevedo, a morte aparece como metáfora para a transição de um mundo idealizado para um mundo cético, conferindo unidade à sua obra. No poema "Lembrança de Morrer", último da primeira parte da Lira, o poeta idealista morre - "Eu deixo a vida como deixa o tédio / Do deserto, o poente caminheiro / (...) / Só levo uma 
saudade - é desses tempos / Que amorosa ilusão embelecia” (2000, p. 188) -, para dar lugar ao cético, como mostrado em "Cadáver de Poeta", primeiro poema da segunda parte da Lira:

\author{
De tanta inspiração e tanta vida \\ Que os nervos convulsivos inflamava \\ E ardia sem conforto... \\ O que resta? uma sombra esvaecida, \\ Um triste que sem mãe agonizava... \\ Resta um poeta morto!" (2000, p. 192).
}

Essa imagem também aparece em Macário, com a morte de Penseroso, o poeta idealista, que decide se suicidar - "a ilusão morreu... Oh! não morrerei com ela? (...) A visão que vesti com a gaza acetinada das minhas ilusões (...) estava no meu coração e só nele (...). Para que sonhar mais o que é impossivel?” (2000, p. 555-556) -, restando apenas Macário, o cético. Se a misantropia é cultivada em "Spleen e Charutos", poema da segunda parte da Lira, não o é por significar um indice de fuga da realidade, como em Soares de Passos, mas sim para acentuar o caráter cético do sujeito lírico: “Deito-me só e triste (...) / Poetas! amanhã ao meu cadáver / Minha tripa cortai mais sonorosa!... / Façam dela uma corda e cantem nela / Os amores da vida esperançosa!" (2000, p. 232-236).

Segundo Vitor Manuel de Aguiar e Silva (1968, p. 436-437), se o romantismo foi uma literatura de evasão, também foi de combate, pois tendia a questionar os valores de sua época; se foi muitas vezes atraído pelo passado, também era uma manifestação de modernidade, pois criou pressupostos estéticos capazes de exprimir os tempos novos; se foi uma arte visionária, também tencionou ser realista, em sua tentativa de abarcar a totalidade. O ultra-romantismo, multifacetado como procuramos mostrar neste artigo, fora, da mesma forma, um convite à heterogeneidade. O mal do século, como defende Silva, não pode ser entendido "como a sintomatologia de almas anêmicas que, desprovidas de audácia para a aventura e isentas de fundos anseios, se fecham receosas em si mesmas" (1968, p. 431-432). A leitura das obras de 
autores como Soares de Passos e Álvares de Azevedo nos revela o seu olhar sobre o contexto político, social e cultural de seu tempo, podendo nos ajudar a desvendar o pensamento de um período mais complexo do que aparenta ser.

\section{Referências bibliográficas:}

AZEVEDO, Manuel Antônio Álvares de. Obra Completa. Rio de Janeiro: Nova Aguilar, 2000.

CANDIDO, Antonio. A educação pela noite. In A Educação pela Noite e outro Ensaios. 2. ed. São Paulo: Ática, 1989, p. 10-22.

Formação da Literatura Brasileira. Momentos Decisivos. vol. II, 2.ed. São Paulo: Martins, 1964.

FALBEL, Nachman. Os fundamentos históricos do romantismo. In GUINSBURG, J. (org.). O Romantismo. 4. ed. São Paulo: Perspectiva, 2002, p. 23-50.

HAUSER, Arnold. Rococó, Classicismo, Romantismo. In História Social da Arte e da Literatura. Trad. Álvaro Cabral. 4. ed. São Paulo: Martins Fontes, 2003, p. 497-726.

PASSOS, António Augusto Soares de. Poesias. Lisboa: Vega, 1983.

REIS, Carlos e PIRES, Maria da Natividade. História Crítica da Literatura Portuguesa: O Romantismo. 5 vol., 2.ed. Lisboa: Verbo, [199?].

SILVA, Vítor Manuel de Aguiar e. Pré-romantismo e romantismo. In Teoria da Literatura. 2. ed. Coimbra: Almedina, 1968, p. 411-439. 